\title{
Terrestrial Permafrost as a Model Environment for Bioastronomy
}

\author{
A. Tsapin \\ Jet Propulsion Laboratory, California Institute of Technology, 4800 Oak \\ Grove Dr. Pasadena, CA 91109, U.S.A.; tsapin@jpl.nasa.gov \\ G. D. McDonald \\ Jet Propulsion Laboratory, California Institute of Technology, 4800 Oak \\ Grove Dr. Pasadena, CA 91109, U.S.A.
}

\begin{abstract}
The extent to which organisms can survive extended periods of metabolic inactivity in cold environments such as permafrost is one of the key questions in the study of life in extreme environments and for astrobiology. Viable bacteria have been cultured from million year-old Siberian permafrost samples, but the relationship between the age of the bacteria and the age of the sediments remains controversial. In this study we analyze the level of racemization of amino acids in permafrost samples collected from several sites in Northern Siberia. We have shown that even during long exposures to low temperatures $\left(-10^{\circ} \mathrm{C}\right.$ to $\left.-15^{\circ} \mathrm{C}\right)$, the bacterial cells in permafrost are not completely dormant, but continue to metabolize and at least partially control the extent of amino acid racemization.
\end{abstract}

\section{Introduction}

There are several reasons why permafrost and cold environments should be considered as relevant to the search for life in the solar system and beyond. Cryospheres are very common in the solar system. All planets and their moons from Mars and outward are cold. If life ever existed there the last resort could be only frozen areas. Also permafrost, as an environment with low and more or less constant temperature, is the region where remnants of life or even dormant forms of life would be preserved for the longest time.

The longevity of (micro)organisms in cold environments is of great interest to bioastronomy since cryospheres are common phenomena in the solar system, particularly on satellites, comets and asteroids, and on some of the planets. Recent data from the Mars Global Surveyor mission suggest the possibility of permafrost or perhaps even liquid water under the Martian surface (Malin \& Edgett 2000). The probability of finding life on Mars, if it exists, is probably higher in such environments. In addition, the evaluation of the possibility of transfer of living organisms between planets via impact ejecta (e.g., Mileikowsky et al. 2000) needs the information on the maximum time over which microor- 
ganisms in cold environments can remain dormant and subsequently revive and reproduce.

Our strategy for the search for extraterrestrial life or its remnants is based on studying the most probable environments in which life (extant or extinct) may be found, and determining the maximum period of time over which such life could be preserved. The terrestrial permafrost, inhabited by cold adapted microbes, can be considered as an extraterrestrial analog environment. The cells and their metabolic end-products in Earth's permafrost can be used in the search for possible ecosystems and potential inhabitants on extraterrestrial cryogenic bodies (Gilichinsky, Soina, \& Petrova 1993). The study of microorganisms (or their remnants) that were buried for a few million years in permafrost provides us with a unique opportunity to determine the long-term viability of (micro)organisms.

Permafrost occupies a significant part of North America and Eurasia, and accounts for around 20\% of Earth's total land surface. Permafrost represents a temperature stable environment that allows the prolonged survival of microbial lineages at subzero temperatures. The first reports of the existence of bacteria in permafrost appeared almost a century ago, in relation to the discovery of mammoths and to studies of soils in Siberia (Omelyansky 1911; Isachenko 1912), and then in Canadian Arctic, Alaska, and Antarctica. Viable bacteria have been isolated and cultured from Siberian permafrost core sections dated by stratigraphy at up to a few million years old (Gilichinsky et al. 1992). Microorganisms from ancient permafrost have been revived and isolated in pure culture (Vorobyova et al. 1997; Vishnivetskaya et al. 2000). Preliminary 16S rRNA analysis of microbial communities from permafrost of different ages (Shi et al. 1997) has also been reported.

Permafrost is a unique environment serving as a "natural gene bank", with many species frozen in time (i.e. preserved in an unchanging evolutionary state). Permafrost presents a golden niche for future biotechnology, and is also a unique environment for studying longevity and survivability microorganisms (pro- and eukaryotes).

Permafrost, alone among cold environments, offers a sedimentary column in which, in a one borehole made in the thick permafrost, we can observe in the preserved genetic material the history of biological evolution during the last several hundred thousand or maybe even a few million years. A thorough study of the phylogenetic relationships of organisms at each depth, as well as comparisons between different depths of permafrost, using molecular evolution techniques, will give us a unique window into the process of evolution of microbial communities over geologic time.

We have analyzed the degree of racemization of aspartic acid in permafrost samples from Northern Siberia, an area from which microorganisms of apparent ages up to a few million years have previously been isolated and cultured. We have found that the extent of aspartic acid racemization in permafrost cores increases very slowly up to an age of approximately 25000 years (around $5 \mathrm{~m}$ depth). The apparent temperature of racemization over the age range $0-25000$ years, determined using measured aspartic acid racemization rate constants, is $-19^{\circ} \mathrm{C}$. This apparent racemization temperature is significantly lower than the measured environmental temperature $\left(-11^{\circ} \mathrm{C}\right.$ to $\left.-13^{\circ} \mathrm{C}\right)$, and suggests active 
recycling of D-aspartic acid in Siberian permafrost up to an age of around 25000 years. This indicates that permafrost organisms are capable of repairing some molecular damage incurred while they are in a "dormant" state over geologic time.

Figure 1 shows the relationship of aspartic acid racemization to ${ }^{14} \mathrm{C}$ age over the upper $40 \mathrm{~m}$ of permafrost. The $y$ axis is the left-hand side of the racemization equation given above, and the $x$ axis is time. Therefore the slope of a linear regression line is equal to $2 k$ for that portion of the plot. We have divided the data by inspection into two groups for linear regression analysis. The first group consists of points from the surface down to ages of around 25000 years (Brinton et al. 2002). The second group contains the remaining points plus the four points at 20,000-25000 years (added to provide a "zero" point for the regression). We obtain a $k$ value of $8.94 \times 10^{-7} \mathrm{yr}^{-1}\left(1.02 \times 10^{-10} \mathrm{hr}^{-1}\right)$ for aspartic acid racemization in the first group, and $5.25 \times 10^{-6} \mathrm{yr}^{-1}\left(5.99 \times 10^{-10} \mathrm{hr}^{-1}\right)$ for the second, deeper group.

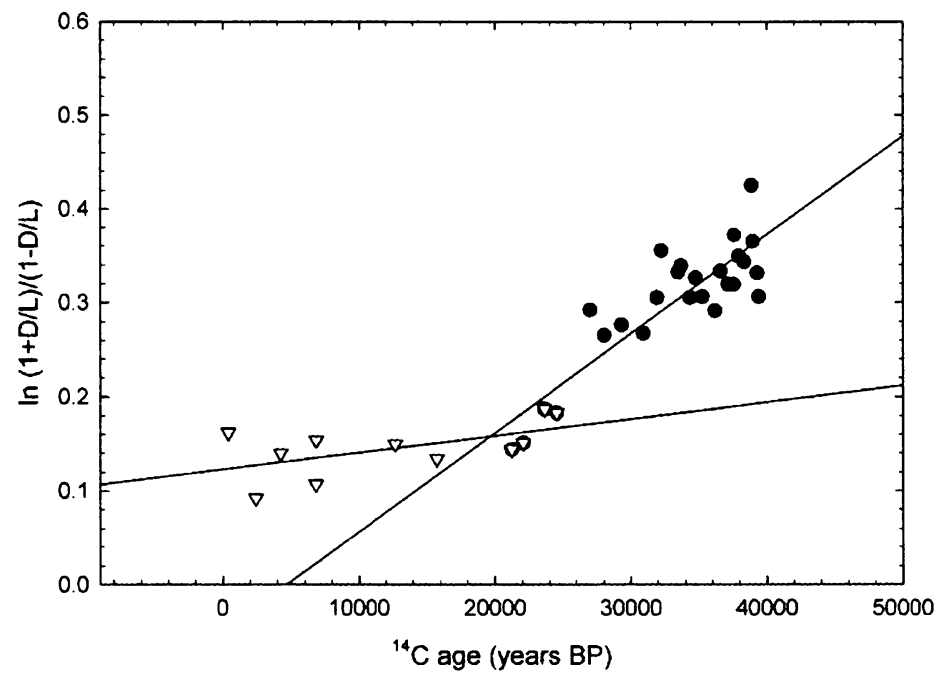

Figure 1. Extent of aspartic acid racemization vs ${ }^{14} \mathrm{C}$ age in Siberian permafrost. $0-25000$ years: $\ln (1+\mathrm{D} / \mathrm{L}) /(1-\mathrm{D} / \mathrm{L})=0.12+1.78 \times$ $10^{-6}$ (age), $r^{2}=0.33$. 20000-40000 years: $\ln (1+\mathrm{D} / \mathrm{L}) /(1-\mathrm{D} / \mathrm{L})=-0.05$ $+1.05 \times 10^{-5}$ (age), $r^{2}=0.77$.

Our explanation for these data is that microorganisms, as they are buried in the permafrost sediments, continue to carry out amino acid metabolism for some time, although at a reduced rate. This continues until the organisms cease metabolism, which appears from our data to be at an age of around 25000 years ( $5 \mathrm{~m}$ depth). At this point, the cells may still be metabolically active at some very low level, but amino acid metabolism has ceased. Since the rate of racemization below this depth is consistent with a lack of metabolism down to the 
oldest samples we have so far analyzed (approximately 40000 years), we suggest that around 25000 years is the "lifetime" over which the organisms can continue to carry out amino acid metabolism in the permafrost environment. This apparent amino acid metabolic "lifetime" does not necessarily imply, however, that no organisms older than 25000 years are capable of reviving under more favorable conditions or in culture. It is not known conclusively how high $\mathrm{D} / \mathrm{L}$ ratios in a cell can rise without interfering with protein synthesis to the extent that the cell would become non-viable. We therefore have evidence from preliminary studies of permafrost samples using these techniques that even during long exposures to low temperatures $\left(-10^{\circ} \mathrm{C}\right.$ to $\left.-15^{\circ} \mathrm{C}\right)$, the bacterial cells in permafrost are not completely dormant, but continue to metabolize and at least partially control the extent of amino acid racemization.

Acknowledgments. The authors thank Ken Nealson and Henry Sun for comments and discussions. Portions of the research described in this paper were carried out at the Jet Propulsion Laboratory, California Institute of Technology, under a contract with the National Aeronautics and Space Administration. Additional funding was provided by the NASA Astrobiology Institute. The authors thank D. Gilichinsky for samples used for this work.

\section{References}

Brinton, K. L. F., Tsapin, A., Gilichinsky, D., \& McDonald, G. D. 2002, Astrobiology, 2, 77

Gilichinsky, D., Vorobyova, E., Erokhina, L., \& Fyodorov-Davydov, D. 1992, Adv. Space Res., 12, 255

Gilichinsky, D., Soina, V., \& Petrova, M. 1993, in Origins Life, 23, 65

Isachenko, B. 1912, Izvestiya Sankt-Peterburgskogo Botanicheskogo Sada, 12, 140

Malin, M. C., \& Edgett, K. S. 2000, Science, 288, 2330

Mileikowsky, C., et al. 2000, Icarus, 145, 391

Omelyansky, V. 1911, Arkhiv Biologicheskikh Nauk, 16, 335

Shi, T., Reevs, R., Gilichinsky, D., \& Friedmann, E. I. 1997, Microbial. Ecology, 33,169

Vishnivetskaya, T., Kathariou, S., McGrath, J., Gilichinsky, D., \& Tiedje, J. M. 2000, Extremophiles, 4, 165

Vorobyova, E., et al. 1997, FEMS Microbiol. Rev., 20, 277 